\title{
Analiza numeryczna procesu spawania łącznika spawalniczego stal-aluminium
}

\author{
Numerical analysis of the welding process of steel-aluminum \\ welding connector
}

\section{Streszczenie}

W pracy zaprezentowano wyniki symulacji procesu spawania łącznika spawalniczego o konfiguracji stal S235JRaluminium A5083 z międzywarstwą tytanu Grade 1 oraz aluminium A1050. W publikacji zaprezentowano parametry materiałowe modelu, a także wyniki pierwszych obliczeń w postaci rozkładów temperatury oraz naprężeń własnych wywołanych przez proces łączenia materiałów.

Słowa kluczowe: metoda elementów skończonych; symulacja; spawanie; łączniki spawalnicze

\begin{abstract}
The paper presents the results of the numeric welding simulation performed for S235JR-aluminum A5083 transition joint. The paper presents material parameters used in the model calculations. Results of the first calculations were presented in the form of the residual stresses distributions induced by the process of joining materials.
\end{abstract}

Keywords: finite element method; simulation; welding; transition joint

\section{Wstęp}

Symulacja procesu spawania materiałów konstrukcyjnych z wykorzystaniem metody elementów skończonych (MES) znajduje coraz szersze zastosowanie w projektowaniu maszyn i urządzeń. Zespolenie nieliniowej analizy termicznej oraz mechanicznej umożliwia między innymi określenie rozkładów temperatury, deformacji i naprężeń wewnętrznych wywołanych procesem spawania. Uzyskane informacje pozwalają na optymalizację procesu łączenia materiałów [3]. W nowoczesnych konstrukcjach inżynierskich często wykorzystuje się połączenia pomiędzy materiałami o różnych właściwościach wytrzymałościowych i mikrostrukturalnych. Przykładem tego typu złączy są połączenia stalaluminium, szeroko stosowane w przemyśle stoczniowym oraz motoryzacyjnym [5]. Technologia spawania umożliwia łączenie stali oraz aluminium z wykorzystaniem ciepła generowanego za pośrednictwem np. łuku elektrycznego. Jednak ciepło doprowadzane do układu może powodować powstawanie kruchej intermetalicznej struktury $\mathrm{Fe}_{x} \mathrm{Al}_{\mathrm{y}}$ co ma istotny wpływ na właściwości wytrzymałościowe uzyskiwanych połączeń np. wytrzymałość na rozciąganie [7]. Alternatywą dla bezpośredniego procesu spawania jest zastosowanie złączy śrubowych lub nitów co w znaczącym stopniu może wpłynąć na masę oraz aspekty ekonomiczne związane z dozorem technicznym maszyn i urządzeń. Zastosowanie kompozytowych łączników spawalniczych, opartych np. o zgrzewane wybuchowo lub walcowane na gorąco materiały wielowarstwowe pozwala na stosowanie technologii spawania bez konieczności prowadzenia dodatkowych zabiegów technologicznych. Wykorzystanie łączników spawalniczych wiąże ze sobą konieczność analizy konstrukcji między innymi pod kątem naprężeń własnych obecnych w konstrukcji. W pracy zaprezentowano wyniki symulacji procesu spawania łącznika spawalniczego o konfiguracji stal S235JR-aluminium A5083 z międzywarstwą tytanu Grade 1 oraz aluminium $\mathrm{A} 1050$.

\section{Właściwości materiałów}

Analizie poddano konstrukcję łącznika składającą się z: aluminium A5083 (5 mm), aluminium A1050 (1,5 mm), tytanu Grade $1(1 \mathrm{~mm})$, stali S235JR+N (5 mm). Wymiary symulowanego układu kompozytu zaprezentowano na rysunku 1.

Obliczenia przeprowadzono z wykorzystaniem analizy nieliniowej dla parametrów materiałowych zmiennych w funkcji temperatury. Dane materiałowe zostały określone na podstawie badań eksperymentalnych (tabl. I) oraz danych dostępnych w literaturze $[1,4,6,8 \div 10]$. Podstawowe właściwości wytrzymałościowe materiałów przed procesem zgrzewania w temperaturze pokojowej zaprezentowano w tablicy I.

Dr inż. Mateusz Kowalski - Politechnika Opolska.

Autor korespondencyjny/Corresponding author. m.kowalski@po.opole.pl 


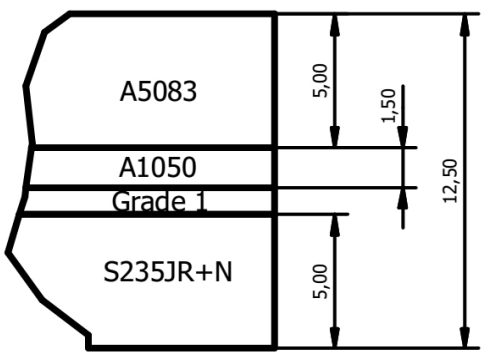

Rys. 1. Wymiary kompozytu wielowarstwowego w milimetrach Fig. 1. Multilayer composite thickness dimensions in millimeters

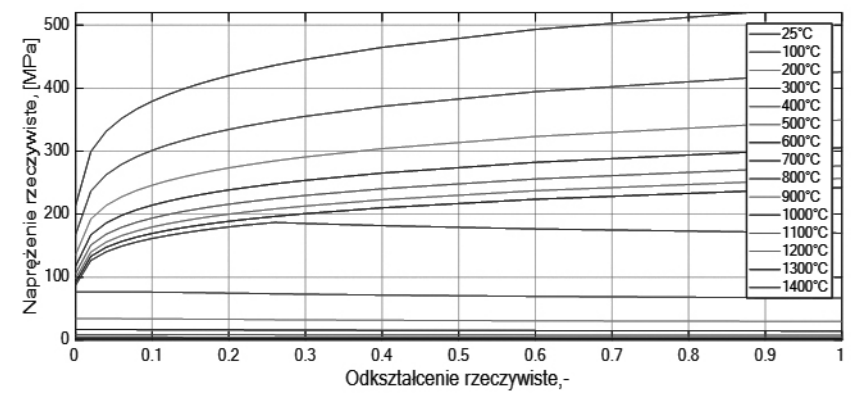

Rys. 2. Krzywe płynięcia stali S235JR+N w zależności od temperatury

Fig. 2. Flow curves for S235JR+N in temperature dependence
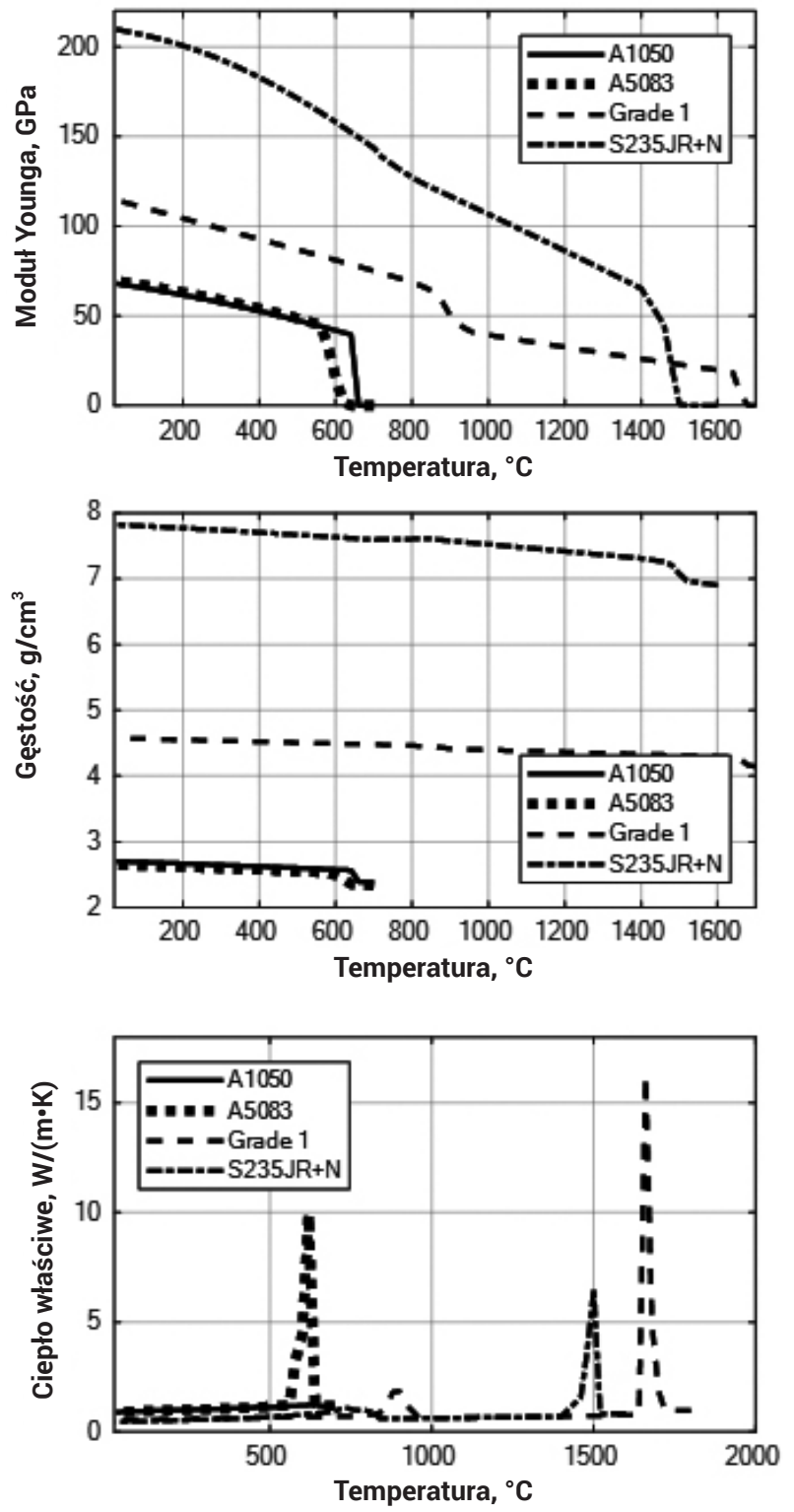

Rys. 3. Właściwości fizyczne materiałów

Fig. 3. Physical properties of the materials
W obliczeniach uwzględniono krzywe płynięcia dla poszczególnych materiałów. W zależności od właściwości materiału powyżej wartości ok. 0,7 temperatury topnienia oddziaływanie zjawiska umocnienia na stabilność obliczeń jest coraz niższe (rys. 2). Na rysunku 3 zaprezentowano właściwości fizyczne materiałów w funkcji temperatury. Dane zostały zaprezentowane $\mathrm{w}$ zakresie od temperatury $25^{\circ} \mathrm{C}$ do temperatury topnienia dla poszczególnych materiałów.

\section{Model obliczeniowy}

Symulacje przeprowadzono dla układu zaprezentowanego na rysunku 4a. W analizie wykorzystano sześcienne elementy skończone. Łączna liczba elementów skończonych wynosiła 10780, liczba węzłów 15840. Połączenia pomiędzy poszczególnymi warstwami kompozytu zdefiniowano w sposób uproszczony, pomijając falisty przebieg złącza charakterystyczny dla kompozytów wytworzonych w technologii wybuchowej (rys. 4b).

W obliczeniach uwzględniono modele spoin. Wysokości oraz długości spoin dla stali i aluminium wynosiły $3 \mathrm{~mm}$. Modele spoin generowano z wykorzystaniem wektora czasu co pozwoliło na symulację prędkości spawania. W obliczeniach uwzględniono parametry technologiczne procesu w postaci
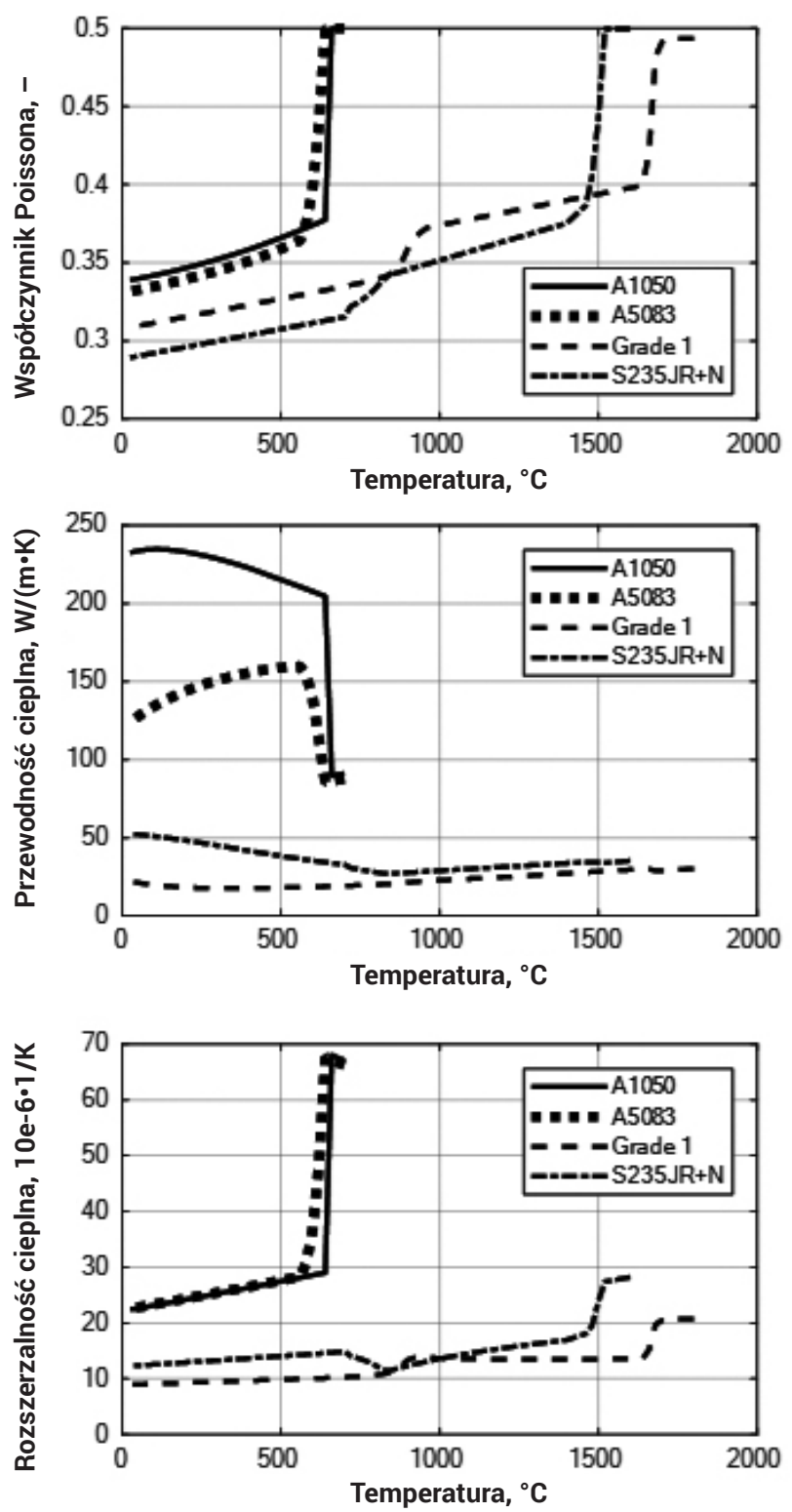
Tablica I. Własności mechaniczne badanych materiałów przed połączeniem, temperatura pokojowa

Table I. Mechanical properties of materials before cladding in the room temperature

\begin{tabular}{|c|c|c|c|c|c|}
\hline \multirow{2}{*}{ Materiał } & \multicolumn{5}{|c|}{ Właściwości wytrzymałościowe } \\
\cline { 2 - 6 } & $\mathbf{R}_{\mathbf{p 0 2}, \mathbf{M P a}}$ & $\mathbf{R}_{\mathrm{m}, \mathbf{M P a}}$ & $\mathbf{E}, \mathbf{M P a}$ & $\mathbf{G}, \mathbf{M P a}$ & $\mathbf{v},-$ \\
\hline Stal S235JR+N & 235 & $350 \div 370$ & 220000 & 84000 & 0,3 \\
\hline Tytan Grade 1 & $189 \div 215$ & $308 \div 324$ & 100000 & 38000 & 0,37 \\
\hline Aluminium A1050 & 20 & $65 \div 95$ & 69000 & 25900 & 0,33 \\
\hline Aluminium A5080 & 125 & $275 \div 350$ & 71000 & 26800 & 0,33 \\
\hline
\end{tabular}
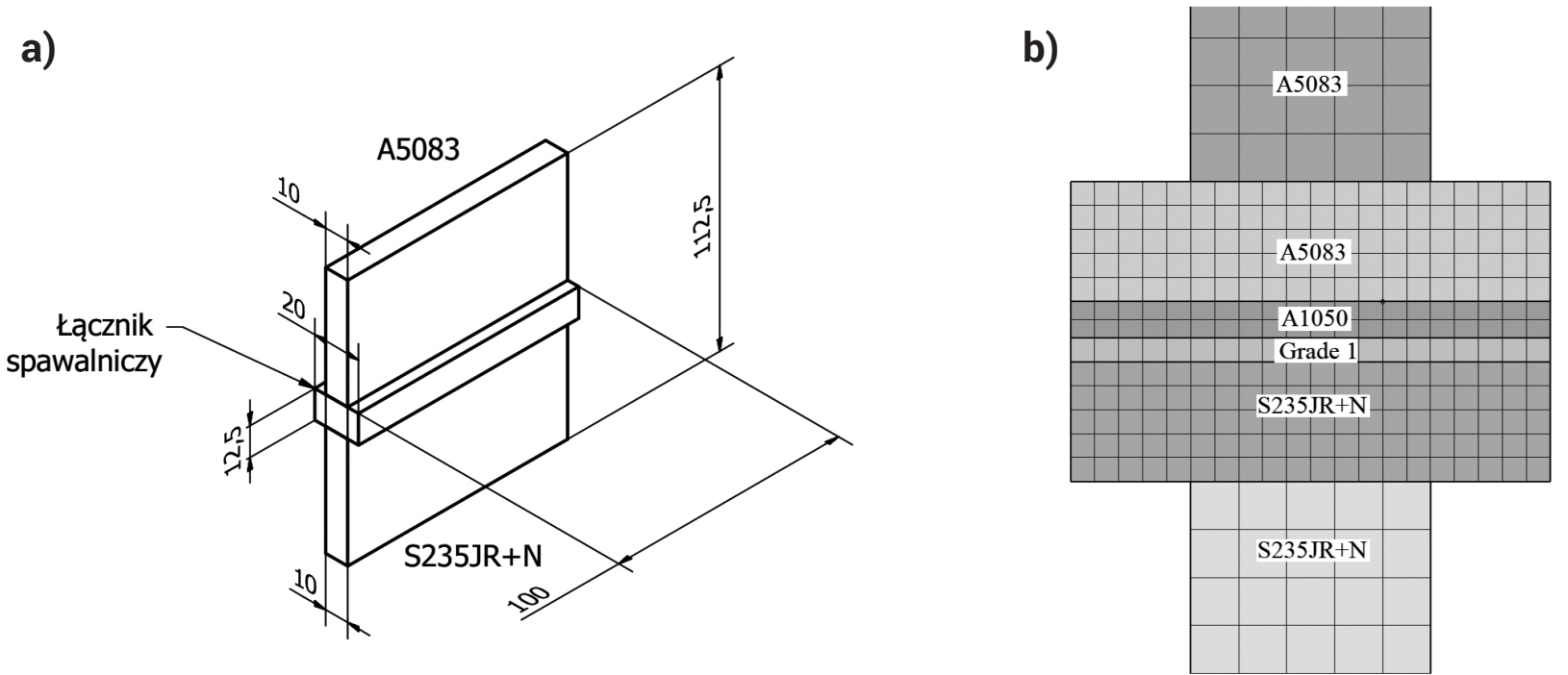

Rys. 4. Model łącznika spawalniczego: a) kształt i wymiary układu, b) siatka elementów skończonych

Fig. 4. Model of welding connector. a) shape and dimensions of the system, b) mesh of finite elements

wolumetrycznego obciążenia układu strumieniem ciepła generowanego wg rozkładu Goldaka [2] (rys. 5) o wymiarach charakterystycznych zaprezentowanych w tablicy II.

Analizę wykonano dla spoin pachwinowych po stronie stali i aluminium z uwzględnieniem rozkładów temperatury i naprężeń własnych. We wszystkich częściach symulowanego układu zastosowano model kinematycznego umocnienia materiału.

\section{Wyniki analizy}

Wyniki analizy przedstawiono $w$ formie warstwic temperatury podczas procesu spawania oraz naprężeń własnych po połączeniu materiałów. Maksymalne wartości temperatur w kompozycie wielowarstwowym mogą być istotne między innymi ze względu na mechanizm powstawania tlenków w złączu stal-tytan w podwyższonych temperaturach.

Na rysunku 7 zaprezentowano przykładowe cykle cieplne dla punktów znajdujących się powierzchni bocznej łącznika obliczone w połowie długości układu. Ze względu na relatywnie niewielką szerokość złącza w materiale wielowarstwowym podczas spawania aluminium A5083 może zachodzić zjawisko oddzielenia warstwy aluminium.
$\mathrm{Na}$ rysunku 8 zaprezentowano wykresy naprężeń własnych obecnych w konstrukcji po procesie spawania wg hipotezy HMH. Maksymalna wartość naprężenia w blasze A5083 wynosiła ok. $150 \mathrm{MPa}$. W złączach materiału wielowarstwowego odnotowano naprężenia w zakresie od 100 do $144 \mathrm{MPa}$. Uzyskane wartości przekraczają granicę plastyczności tytanu Grade 1 oraz aluminium A1050. Wzrost naprężenia w warstwie stalowej w odległości ok. $50 \mathrm{~mm}$ od złącza spawanego wynika z kolejności łączenia elementów. Proces spawania aluminium powoduje deformację łącznika, która powoduje zjawisko zginania blachy stalowej.

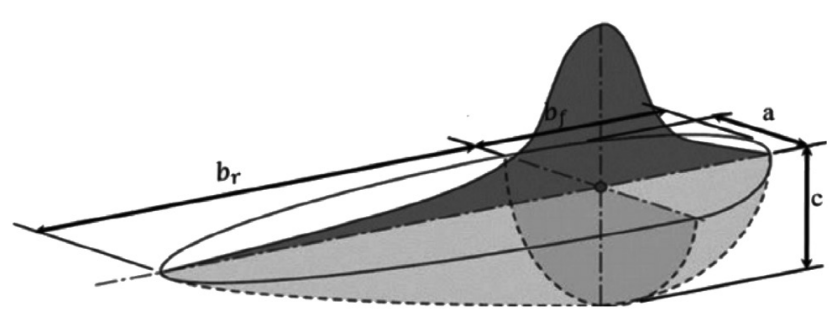

Rys. 5. Model rozkładu ciepła wg Goldaka

Fig. 5. Goldak model of heat distribution

Tablica II. Parametry procesu spawania oraz zastosowanego źródła ciepła Table II. Welding and heat source parameters

\begin{tabular}{|c|c|c|c|c|c|c|c|}
\hline \multirow{2}{*}{ Materiał } & \multicolumn{3}{|c|}{ Parametry spawania } & \multicolumn{4}{|c|}{ Parametry źródła ciepła } \\
\hline & $\mathrm{I}[\mathrm{A}]$ & $\mathrm{V}[\mathrm{V}]$ & $\mathrm{v}[\mathrm{cm} / \mathrm{min}]$ & $b_{f}[\mathrm{~mm}]$ & $b_{r}[\mathrm{~mm}]$ & $\mathrm{a}[\mathrm{mm}]$ & $\mathrm{c}[\mathrm{mm}]$ \\
\hline Aluminium & 230 & 22,8 & 30 & 2.2 & 7,2 & 2,7 & 3,7 \\
\hline Stal & 220 & 26,5 & 30 & 2.5 & 7,2 & 2,6 & 3,5 \\
\hline
\end{tabular}

Gdzie: $b_{f}, b_{r}$ - kolejno długości frontowej i tylnej części rozkładu, a - połowa szerokości rozkładu źródła ciepła, c - głębokość penetracji źródła ciepła 
a)
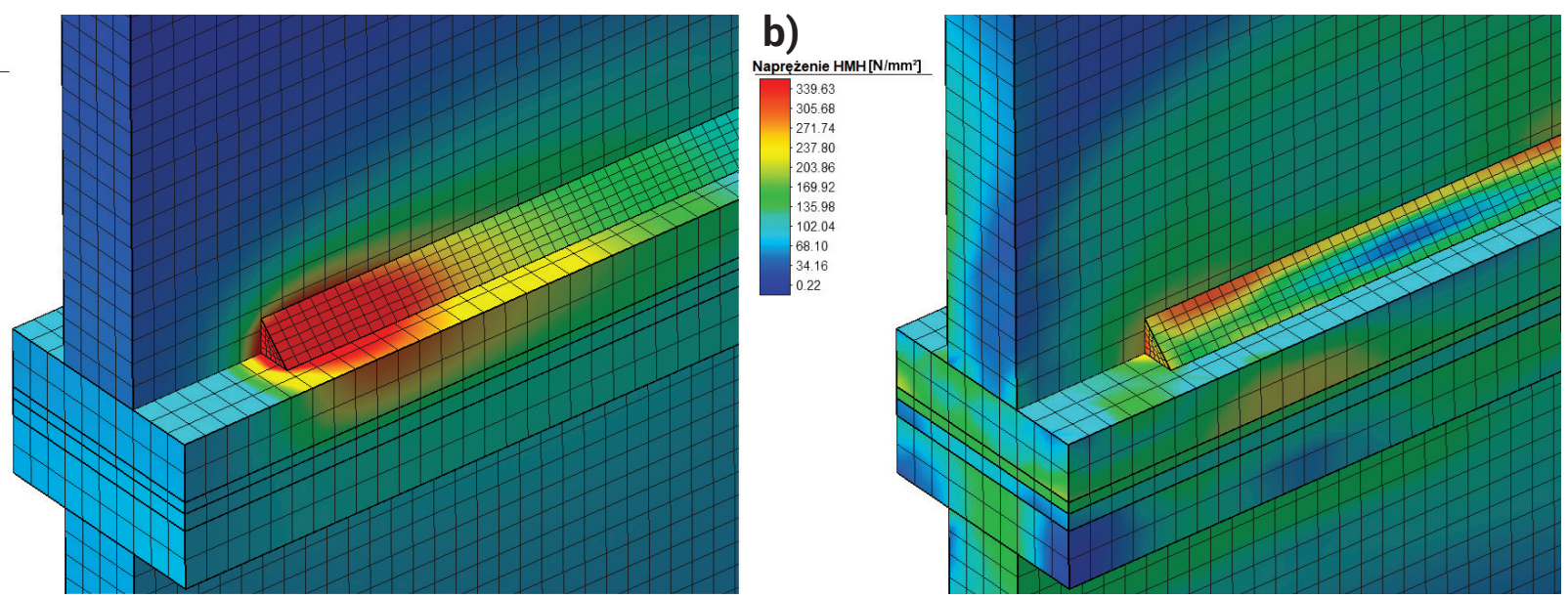

Rys. 6. Wyniki analizy: a) temperatura podczas spawania stali, b) naprężenia własne wg hipotezy HMH po czasie 500s

Fig. 6. Analysis results: a) temperature during steel welding, b) residual stress $(\mathrm{HMH})$ after $500 \mathrm{~s}$

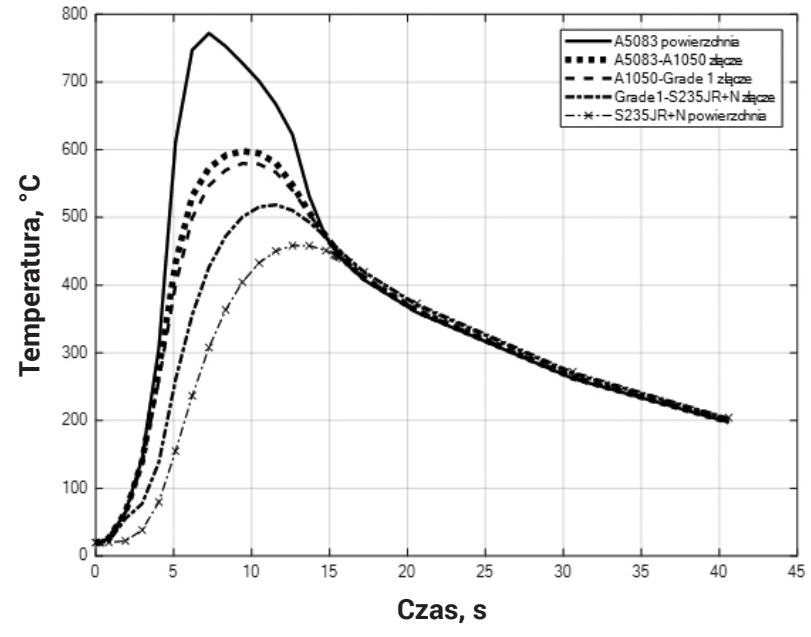

Rys. 7. Cykle cieplne punktów na powierzchni łącznika

Fig. 7. Thermal cycles of points on the surface of the transition plate

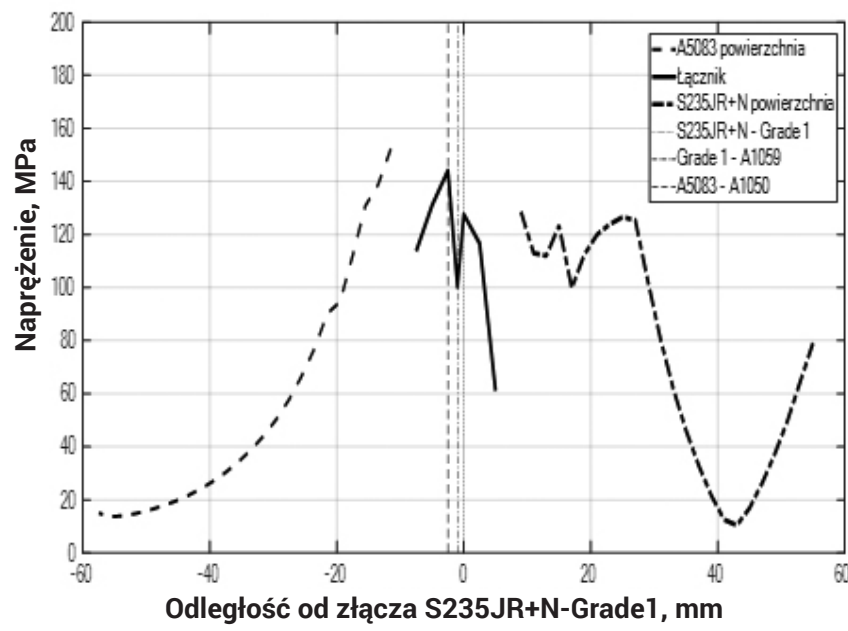

Rys. 8. Naprężenia własne w konstrukcji łącznika po procesie spawania Fig. 8. Residual stresses in the transition joint after the welding process

\section{Wnioski i spostrzeżenia}

Na podstawie przeprowadzonych badań sformułowano następujące wnioski i spostrzeżenia:

- Maksymalne wartości naprężeń ok. $150 \mathrm{MPa}$ odnotowano w blasze A5083. W materiale wielowarstwowym naprężenia zawierały się w przedziale od ok. 100 do $140 \mathrm{MPa}$.

- Zastosowanie metody elementów skończonych umożliwia określenie naprężeń wywołanych procesem spawania łącznika. Model wymaga eksperymentalnej weryfikacji poprzez pomiar naprężeń własnych np. z zastosowaniem metod trepanacyjnych.

- Parametry procesu spawania mogą wpływać na optymalną konfigurację konstrukcji łącznika (szerokość płyty kompozytu). Zwiększenie objętości materiału spowoduje odprowadzanie większej ilości ciepła podczas spawania zapobiegając np. zjawisku delaminacji złącza.

\section{Literatura}

[1] Altenpohl D.: Aluminium und Aluminiumlegierungen, Springer-Verlag, Berlin Heidelberg, 1965.

[2] Goldak J., Chakravarti A., Bibby M.: A new finite element model for weIding heat sources, MTB. 15, 1984, pp. 299-305.

[3] Knoedel P., Gkatzogiannis S., Ummenhofer T.: Practical aspects of weIding residual stress simulation, Journal of Constructional Steel Research. 132, 2017, pp. 83-96.

[4] Kumar Singh S., Mohan Tiwari R., Kumar A., Kumar S., Qasim Murtaza, S. Kumar. Mechanical Properties and Microstructure of Al-5083 by TIG, Materials Today: Proceedings. 5, 2018, pp. 819-822.

[5] Liu W., Ma J., Mazar Atabaki M., Kovacevic R.: Joining of advanced highstrength steel to AA 6061 alloy by using Fe/Al structural transition joint, Materials \& Design. 68, 2015, pp. 146-157.
[6] Purdue University, Thermophysical Properties Research Center, Y.S. Touloukian, C.Y. Ho: Properties of aluminum and aluminum alloys, Thermophysical Properties Research Center, Purdue University, West Lafayette, Ind., 1973.

[7] Rathod M., Kutsuna M.: Joining of Aluminum Alloy 5052 and Low-Carbon Steel by Laser Roll Welding, Welding Journal., 2004, pp. 16-26.

[8] Schoer H.: Schweißen und Hartlöten von Aluminiumwerkstoffen, 2nd ed., DVS Media GmbH, Düsseldorf, 2003.

[9] Seyffarth P., Scharff A., Meyer B.: Grosser Atlas Schweiss-ZTUSchaubilder, DVS Me-dia GmbH, Düsseldorf, 1992.

[10] Yogo Y., Sawamura M., Harada R., Miyata K., Iwata N., Ishikawa T.: Stressstrain curve of pure aluminum in a super large strain range with strain rate and temperature dependency, Procedia Engineering. 207, 2017, pp. 161-166. 